\title{
Series Solutions of Lifting and Drainage Problems of a Nonisothermal Modified Second Grade Fluid Using a Vertical Cylinder
}

\author{
M. Farooq, ${ }^{1}$ M. T. Rahim, ${ }^{1}$ S. Islam, ${ }^{2}$ and M. Arif ${ }^{2}$ \\ ${ }^{1}$ Department of Mathematics, National University of Computer \& Emerging Sciences, Peshawar, Pakistan \\ ${ }^{2}$ Department of Mathematics, Abdul Wali Khan University, Mardan, KPK, Pakistan \\ Correspondence should be addressed to M. Arif; marifmaths@yahoo.com
}

Received 3 June 2013; Accepted 14 January 2014; Published 24 February 2014

Academic Editor: Saeid Abbasbandy

Copyright (c) 2014 M. Farooq et al. This is an open access article distributed under the Creative Commons Attribution License, which permits unrestricted use, distribution, and reproduction in any medium, provided the original work is properly cited.

We studied the thin film flow for lifting and drainage problems using an incompressible, nonisothermal modified second grade fluid. We developed nonlinear differential equations from momentum and energy equations, respectively. Series solutions for both lifting and drainage problems are obtained. Expressions for the velocity profile, temperature distribution, volume flux, average film velocity, and shear stress on cylinder for both cases are obtained. Effects of different parameters on the flow problems are presented graphically.

\section{Introduction}

Thin film flows of linearly viscous fluids have been the subject of deep investigation for the last few decades. This is because of the widespread applications of such flows, both industrial and natural. The literature on thin film flows for Newtonian fluids is far-reaching but no proper attention has been given to these flows concerning non-Newtonian fluids. Siddiqui et al. [1-4] and Hayat et al. [5-7] made their valuable contributions to the thin film flows of non-Newtonian fluids. The most common examples of the non-Newtonian fluids are paints, clay coatings and other suspensions, drilling mud, blood, shampoo, ketchup, polymer melts, certain oils and greases, clastomers, and many other emulsions. Because of the fact that a single constitutive equation cannot exhibit all properties of non-Newtonian fluids, many constitutive equations or models have been proposed. Among these, the differential type fluids $[8,9]$ have received exceptional consideration. The modified second grade fluids, a subclass of the fluids of differential type, have been studied effectively in various types of flow situations [10-13].
The flow of Newtonian fluids is described by the NavierStokes equations which are nonlinear partial differential equations and the exact solutions of these equations are very rare. The importance of exact solutions is not only because of the fact that they are the solutions of some fundamental flows but also because they are used as accuracy check for experimental, asymptotic, and numerical methods. The governing equations that describe the flow of non-Newtonian fluids are more complex and nonlinear than the NavierStokes equations and so the exact solutions obtained for these equations are considered as milestone.

Many researchers have been attracted by the flow and heat transfer inside thin films [14-16]. This is due to their vast applications in engineering and industry such as food stuff processing, fiber and wire coating, reactor fluidization, transpiration cooling, polymer processing, gaseous diffusion, heat pipes, and fluidic cells of many biological and chemical detection systems. Lavrik et al. [17] considered the problem of chambers for chemical and biological detection systems such as fluidic cells for biological and chemical microcantilever. In majority of the problems related to flow and heat 
transfer studies, the power-law fluid model is taken as the non-Newtonian fluid. Only unpretentious interest has been devoted to the studies where the effects of viscous dissipation are incorporated, although its importance has been shown in many cases such as polymer processing.

The aim of the present paper is to discuss two different flow problems for the modified second grade fluid motion on a vertically upward moving cylinder and down a stationary vertical cylinder. Series solutions subject to appropriate boundary conditions of the modeled highly nonlinear differential equations are obtained in both cases. Because of their practical significance, expressions for velocity profile, temperature distribution, volume flux, average film velocity, and shear stress on cylinder are also calculated. To the best of our knowledge, these kinds of problems with heat transfer have not yet been reported. At the end, graphical results are presented for different physical parameters appearing in the solution. We observed that modified second grade fluid shows the power law model results for steady case.

This paper is organized as follows. In Section 2, basic equations for the modified second grade fluid model are given. Section 3 provides formulation and solution of the lifting problem. Section 4 calculates volume flux, average film velocity, and shear stress on cylinder for lifting problem. Section 5 consists of equations and their solutions for drainage problem. Volume flux, average film velocity, and shear stress on cylinder for drainage problem are calculated in Section 6. Section 7 contains results and discussion, while concluding remarks are given in Section 8.

\section{Basic Equations}

The basic equations governing the flow of an incompressible, non-Newtonian fluid including thermal effects are [18]

$$
\begin{gathered}
\operatorname{div} \mathbf{V}=0, \\
\rho \frac{D \mathbf{V}}{D t}=\rho \mathbf{f}-\operatorname{grad} p+\operatorname{div} \mathbf{T}, \\
\rho C_{p} \frac{D \Theta}{D t}=\kappa \nabla^{2} \Theta+\mathbf{T} \cdot \mathbf{L},
\end{gathered}
$$

where $\mathbf{V}$ is velocity vector and $D / D t$ is the material time derivative defined as

$$
\frac{D}{D t}(*)=\left(\frac{\partial}{\partial t}+\mathbf{V} \cdot \nabla\right)(*)
$$

where $\rho$ is constant density, $\mathbf{f}$ is body force, $p$ is dynamic pressure, $\Theta$ is temperature, $C_{p}$ is specific heat constant, $\kappa$ is thermal conductivity, and $\mathbf{T}$ is extra stress tensor which is defined differently for different fluids. We have chosen the modified second grade fluid for our study. The extra stress tensor for such a fluid is given by

$$
\mathbf{T}=\mu_{\mathrm{eff}} \mathbf{A}_{1}+\alpha_{1} \mathbf{A}_{2}+\alpha_{2} \mathbf{A}_{1}^{2}
$$

where $\alpha_{1}$ and $\alpha_{2}$ are normal stress coefficients, $\mu_{\text {eff }}$ is an effective viscosity for modified second grade fluid as a function of the shear rate and is defined as

$$
\mu_{\mathrm{eff}}=\eta\left(\frac{1}{2} \operatorname{tr} \mathbf{A}_{1}^{2}\right)^{m / 2}
$$

where $\eta$ is flow consistency index and $m$ is flow behavior index. The Rivlin Ericksen tensors, $\mathbf{A}_{1}$ and $\mathbf{A}_{2}$, are defined as

$$
\begin{aligned}
& \mathbf{A}_{1}=\mathbf{L}+\mathbf{L}^{\mathbf{T}}, \quad \mathbf{L}=\operatorname{grad} \mathbf{V}, \\
& \mathbf{A}_{2}=\frac{D \mathbf{A}_{1}}{D t}+\mathbf{A}_{1} \mathbf{L}+\mathbf{L}^{\mathbf{T}} \mathbf{A}_{1} .
\end{aligned}
$$

It is worthwhile to mention here that, for $m<0$, the fluid is pseudoplastic or shear thinning; for $m>0$, the fluid is dilatant or shear thickening; for $m=0$, we obtain second grade fluid model. On the other hand, if $\alpha_{1}=\alpha_{2}=0$, (5) reduces to the power-law model. Furthermore, if $m=$ $\alpha_{1}=\alpha_{2}=0$, we obtain the classical Newtonian model. It is important to note that the flow behavior index $m$ has the limits $-1<m<1$ [19].

\section{Lifting Problem}

A modified second grade fluid is flowing on the outer surface of an infinitely long vertical cylinder of radius $R$ which moves vertically upward with constant speed $V_{0}$ as illustrated in Figure 1(a). The flow is in the form of a thin uniform axisymmetric film of thickness $\delta$ in contact with stationary air. Gravity effects are in downward direction. We choose $z$-axis in the middle of the cylinder and $r$ is normal to it. Furthermore, we suppose that motion is steady and there is no variation with respect to the component $\Theta$. Thus, velocity field is chosen as

$$
\mathbf{V}=[0,0, w(r)], \quad \Theta=\Theta(r) .
$$

Using profile (8), the continuity equation (1) is identically satisfied and the momentum equation (2) reduces to

$$
\begin{gathered}
0=-\frac{\partial p}{\partial r}+\left(2 \alpha_{1}+\alpha_{2}\right) \frac{1}{r} \frac{d}{d r}\left[r\left(\frac{d w}{d r}\right)^{2}\right], \\
0=-\frac{1}{r} \frac{\partial p}{\partial \theta} \\
0=-\rho g-\frac{\partial p}{\partial z}+\frac{\eta}{r} \frac{d}{d r}\left[r\left(\frac{d w}{d r}\right)^{m+1}\right] .
\end{gathered}
$$

The velocity profile is obtained from (11). If we consider $p$ atmospheric pressure and therefore a constant, then we can take $\partial p / \partial z=0$; therefore, (11) becomes

$$
\frac{1}{r} \frac{d}{d r}\left[r\left(\frac{d w}{d r}\right)^{m+1}\right]=\frac{\rho g}{\eta},
$$

which is highly nonlinear ordinary differential equation. Using profile (8) in the energy equation (3), we obtain

$$
\kappa\left[\frac{d^{2} \Theta}{d r^{2}}+\frac{1}{r} \frac{d \Theta}{d r}\right]+\eta\left[\frac{d w}{d r}\right]^{m+2}=0 .
$$




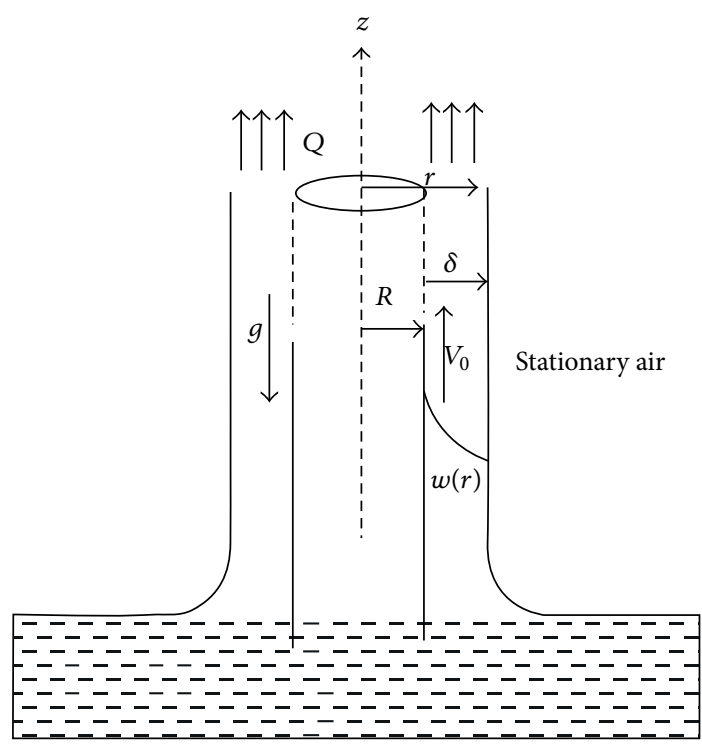

(a)

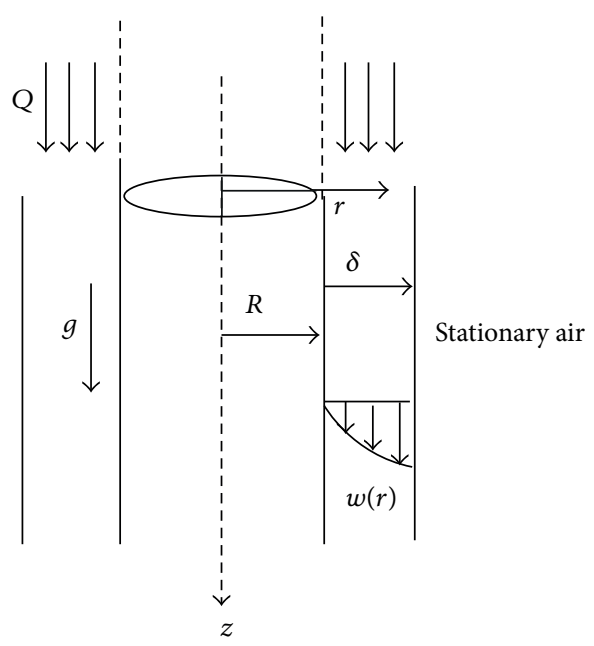

(b)

Figure 1: Geometry of the problems.

The corresponding boundary conditions are

$$
\begin{aligned}
& \text { at } r=R+\delta, \quad \frac{d w}{d r}=0, \quad \frac{d \Theta}{d r}=0, \\
& \text { at } r=R, \quad w=U, \quad \Theta=\Theta_{0} \text {. }
\end{aligned}
$$

Integrating (12) with respect to $r$ and applying the free space boundary condition (14), we get

$$
\frac{d w}{d r}=-\left(\frac{\rho g}{2 \eta}\right)^{1 /(m+1)} \frac{(R+\delta)^{2 /(m+1)}}{r^{1 /(m+1)}}\left[1-\left(\frac{r}{R+\delta}\right)^{2}\right]^{1 /(m+1)} .
$$

In this expression, the sign of $d w / d r$ is always opposite to that of $r$, since velocity decreases with the increase of $r$. The above equation can also be written as

$$
\begin{aligned}
\frac{d w}{d r}= & -\left(\frac{\rho g}{2 \eta}\right)^{1 /(m+1)}(R+\delta)^{2 /(m+1)} \\
& \times \sum_{i=0}^{\infty}\left(\frac{1}{m+1}\right) \frac{(-1)^{i}}{(R+\delta)^{2 i}} r^{2 i-1 /(m+1)} .
\end{aligned}
$$

For $m \neq 0$, solutions of (17) and (13), when boundary conditions (14) and (15) are applied, are

$$
\begin{aligned}
w=U & -\left(\frac{\rho g}{2 \eta}\right)^{1 /(m+1)} \\
\times \sum_{i=0}^{\infty}\left(\frac{1}{m+1}\right) & \times \frac{(-1)^{i+1} R^{(2 i+m /(m+1))}}{(2 i+m /(m+1))(R+\delta)^{2 i-2 /(m+1)}} \\
& \times\left[1-\left(\frac{r}{R}\right)^{2 i+m /(m+1)}\right], \\
\Theta=\Theta_{0}+ & \frac{\eta}{\mathcal{K}}\left(\frac{\rho g}{2 \eta}\right)^{(m+2) /(m+1)} \\
\times \sum_{i=0}^{\infty} & \left(\frac{m+2}{m+1}\right) \frac{(-1)^{i}}{(2 i+m /(m+1))(R+\delta)^{2 i-2((m+2) /(m+1))}} \\
& \times\left[\frac{R^{2 i+m /(m+1)}}{(2 i+m /(m+1))}\left\{1-\left(\frac{r}{R}\right)^{2 i+m /(m+1)}\right\}\right. \\
& \left.+(R+\delta)^{2 i+m /(m+1)} \ln \left(\frac{r}{R}\right)\right]
\end{aligned}
$$

Introducing the nondimensional parameters,

$$
r^{*}=\frac{r}{R}, \quad w^{*}=\frac{w}{U}, \quad \delta^{*}=\frac{\delta}{R},
$$

$$
\Theta^{*}=\frac{\Theta-\Theta_{0}}{\Theta_{1}-\Theta_{0}}, \quad S_{t}=\frac{\rho g R^{2}}{U \mu_{\mathrm{eff}}}, \quad B_{r}=\frac{U^{2} \mu_{\mathrm{eff}}}{\kappa\left(\Theta_{1}-\Theta_{0}\right)},
$$

where $\Theta_{1}$ is reference temperature, $S_{t}$ is Stokes number, and $B_{r}$ is Brinkman number, (18) and (19), after dropping "*”, become

$$
\begin{aligned}
w=1 & +\left(\frac{S_{t}}{2}\right)^{1 /(m+1)} \\
\times \sum_{i=0}^{\infty} & \left(\frac{1}{m+1}\right) \frac{(-1)^{i}}{(2 i+m /(m+1))(1+\delta)^{2 i-2 /(m+1)}} \\
& \quad \times\left[1-r^{2 i+m /(m+1)}\right],
\end{aligned}
$$




$$
\begin{aligned}
\Theta= & B_{r}\left(\frac{S_{t}}{2}\right)^{(m+2) /(m+1)} \\
\times & \left.\sum_{i=0}^{\infty}\left(\frac{m+2}{m+1}\right) \frac{(-1)^{i}}{i}\right) \\
\times & {\left[\frac{1}{(2 i+m /(m+1))(1+\delta)^{2 i}}\right.} \\
+(1+\delta)^{2 i+m /(m+1)} & \ln r],
\end{aligned}
$$$$
\times\left[\frac{(R+\delta)^{2 i+m /(m+1)}}{(2 i+m /(m+1)+2)}\right.
$$$$
\times\left\{\frac{1-(R /(R+\delta))^{2 i+m /(m+1)+2}}{2\left[1-(R /(R+\delta))^{2}\right]}\right\}
$$$$
\left.-R^{2 i+m /(m+1)}\right] \text {. }
$$

which are the dimensionless velocity profile and temperature distribution for modified second grade fluid, respectively.

\section{Volume Flux, Average Film}

\section{Velocity, and Shear Stress on Cylinder for Lifting Problem}

Volume flux, Q, in cylindrical coordinates is given by

$$
Q=\int_{R}^{R+\delta} \int_{0}^{2 \pi} r w(r) d \theta d r
$$

Using profile (18), (22) becomes

$$
\begin{aligned}
& Q= \pi U(R+\delta)^{2}\left[1-\left(\frac{R}{R+\delta}\right)^{2}\right] \\
&-2 \pi\left(\frac{\rho g}{2 \eta}\right)^{1 /(m+1)} \\
& \times \sum_{i=0}^{\infty}\left(\frac{1}{m+1}\right) \frac{(-1)^{i}}{(2 i+m /(m+1))(R+\delta)^{2 i-2 /(m+1)}} \\
& \times \\
& \quad\left[\frac{(R+\delta)^{2 i+m /(m+1)+2}}{(2 i+m /(m+1)+2)}\right. \\
& \quad \times\left\{1-\left(\frac{R}{R+\delta}\right)^{2 i+m /(m+1)+2}\right\} \\
&\left.\quad-\frac{(R+\delta)^{2}}{2} R^{2 i+m /(m+1)}\left\{1-\left(\frac{R}{R+\delta}\right)^{2}\right\}\right]
\end{aligned}
$$

The average film velocity, $\bar{V}$, is defined as

$$
\bar{V}=\frac{Q}{\pi\left[(R+\delta)^{2}-R^{2}\right]} .
$$

Therefore, $\bar{V}$ for the upward moving cylinder is given by

$$
\begin{aligned}
\bar{V}= & U-\left(\frac{\rho g}{2 \eta}\right)^{1 /(m+1)} \\
& \times \sum_{i=0}^{\infty}\left(\frac{1}{m+1}\right) \frac{(-1)^{i}}{(2 i+m /(m+1))(R+\delta)^{2 i-2 /(m+1)}}
\end{aligned}
$$

Shear stress on cylinder is

$$
\left.\mathbf{T}_{r z}\right|_{r=R}=-\frac{\rho g(R+\delta)^{2}}{2 R}\left[1-\left(\frac{R}{R+\delta}\right)^{2}\right] .
$$

\section{Drainage Problem}

Again, we consider a modified second grade fluid now falling on the outer surface of a stationary infinitely long vertical cylinder of radius $R$ (Figure $1(b)$ ). The flow is in the downward direction due to gravity. The governing equations (2) and (3) become

$$
\begin{gathered}
\frac{1}{r} \frac{d}{d r}\left[r\left(\frac{d w}{d r}\right)^{m+1}\right]=-\frac{\rho g}{\eta}, \\
\kappa\left[\frac{d^{2} \Theta}{d r^{2}}+\frac{1}{r} \frac{d \Theta}{d r}\right]+\eta\left[\frac{d w}{d r}\right]^{m+2}=0,
\end{gathered}
$$

along with the corresponding boundary conditions

$$
\begin{aligned}
& \text { at } r=R+\delta, \quad \frac{d w}{d r}=0, \quad \frac{d \Theta}{d r}=0, \\
& \text { at } r=R, \quad w=0, \quad \Theta=\Theta_{0} \text {. }
\end{aligned}
$$

Solving (27) for $m \neq 0$, with boundary conditions (28) and (29), we obtain

$$
\begin{aligned}
w= & \left(\frac{\rho g}{2 \eta}\right)^{1 /(m+1)} \\
& \times \sum_{i=0}^{\infty}\left(\frac{1}{m+1}\right) \frac{(-1)^{i+1} R^{(2 i+m /(m+1))}}{(2 i+m /(m+1))(R+\delta)^{2 i-2 /(m+1)}} \\
& \times\left[1-\left(\frac{r}{R}\right)^{2 i+m /(m+1)}\right] \\
\Theta= & \Theta_{0}+\frac{\eta}{\kappa}\left(\frac{\rho g}{2 \eta}\right)^{(m+2) /(m+1)} \\
& \times \sum_{i=0}^{\infty}\left(\frac{m+2}{m+1}\right) \frac{(-1)^{i}}{(2 i+m /(m+1))(R+\delta)^{2 i-2((m+2) /(m+1))}}
\end{aligned}
$$




$$
\begin{gathered}
\times\left[\frac{R^{2 i+m /(m+1)}}{(2 i+m /(m+1))}\left\{1-\left(\frac{r}{R}\right)^{2 i+m /(m+1)}\right\}\right. \\
\left.+(R+\delta)^{2 i+m /(m+1)} \ln \left(\frac{r}{R}\right)\right] .
\end{gathered}
$$

Using the nondimensional parameters, (20), (30), and (31) in the dimensionless forms, when the "*" is dropped, become

$$
\begin{aligned}
w=\left(\frac{S_{t}}{2}\right)^{1 /(m+1)} & \quad \sum_{i=0}^{\infty}\left(\frac{1}{m+1}\right) \frac{(-1)^{i+1}}{(2 i+m /(m+1))(1+\delta)^{2 i-2 /(m+1)}} \\
& \times\left[1-r^{2 i+m /(m+1)}\right] \\
\Theta= & B_{r}\left(\frac{S_{t}}{2}\right)^{(m+2) /(m+1)} \\
& \times \sum_{i=0}^{\infty}\left(\frac{m+2}{m+1}\right) \frac{(-1)^{i}}{i}(2 i+m /(m+1))(1+\delta)^{2 i} \\
\quad & {\left[\frac{1}{(2 i+m /(m+1))}\left\{1-r^{2 i+m /(m+1)}\right\}\right.} \\
& \left.+(1+\delta)^{2 i+m /(m+1)} \ln r\right] .
\end{aligned}
$$

\section{Volume Flux, Average Film Velocity, and Shear Stress on Cylinder for Drainage Problem}

Volume flux, $Q$, is calculated from (22) by using (30), which is

$$
\begin{aligned}
& Q=2 \pi\left(\frac{\rho g}{2 \eta}\right)^{1 /(m+1)} \\
& \times \sum_{i=0}^{\infty}\left(\frac{1}{m+1}\right) \frac{(-1)^{i}}{(2 i+m /(m+1))(R+\delta)^{2 i-2 /(m+1)}} \\
& \times\left[\frac{(R+\delta)^{2 i+m /(m+1)+2}}{(2 i+m /(m+1)+2)}\right. \\
& \quad \times\left\{1-\left(\frac{R}{R+\delta}\right)^{2 i+m /(m+1)+2}\right\} \\
&\left.\quad-\frac{(R+\delta)^{2}}{2} R^{2 i+m /(m+1)}\left\{1-\left(\frac{R}{R+\delta}\right)^{2}\right\}\right] .
\end{aligned}
$$

The average film velocity, $\bar{V}$, is then given by

$$
\begin{aligned}
& \bar{V}=\left(\frac{\rho g}{2 \eta}\right)^{1 /(m+1)} \\
&\left.\times \sum_{i=0}^{\infty}\left(\frac{1}{m+1}\right) \frac{(-1)^{i}}{i}\right) \frac{m /(m+1))(R+\delta)^{2 i-2 /(m+1)}}{(2 i+)^{2 i+m /(m+1)}} \\
& \times\left[\frac{(R+\delta /(m+1)+2)}{(2 i+m /(m)}\right] \\
& \quad \times\left\{\frac{1-(R /(R+\delta))^{2 i+m /(m+1)+2}}{2\left[1-(R /(R+\delta))^{2}\right]}\right\} \\
&\left.\quad-R^{2 i+m /(m+1)}\right] .
\end{aligned}
$$

Shear stress on cylinder is

$$
\left.\mathbf{T}_{r z}\right|_{r=R}=\frac{\rho g(R+\delta)^{2}}{2 R}\left[1-\left(\frac{R}{R+\delta}\right)^{2}\right] .
$$

\section{Results and Discussion}

In this paper, we studied thin film flows for lifting and drainage problems using vertical cylinders for an incompressible, nonisothermal modified second grade fluid. The series solutions of differential equations for both cases are obtained. Dependence of the flow behavior index, $m$, Stokes number, $S_{t}$, and Brinkman number, $B_{r}$, on velocity profile and temperature distribution is investigated. The effect of flow behavior index, $m$, on velocity field and temperature distribution for both problems is illustrated graphically through Figures 2 and 5. Figures 3 and 6 show the effect of $S_{t}$ and $B_{r}$ numbers on velocity and temperature for dilatant fluids. Graphs for pseudoplastic fluids are given in Figures 4 and 7. For the case of lifting, Figure 2(a) shows that as the fluid is becoming thicker, the magnitude of velocity decreases and vice versa, while the drainage problem is given in Figure 2(b). In Figure 5, we see that as the fluid is becoming thicker, the temperature increases. Figure 3(a) is showing the effect of Stokes number, $S_{t}$, on velocity profile for lifting problem. We see that as $S_{t}$ is increasing, the gradient of velocity decreases, where as in the case of drainage problem Figure 3(b) shows that as $S_{t}$ increases, velocity also increases. The effect of Stokes number, $S_{t}$, and Brinkman number, $B_{r}$, on heat transfer for both problems can be observed in Figures 6(a) and 6(b), respectively. It is evident from these figures that increasing $S_{t}$ and $B_{r}$ numbers results in the rise of temperature. Respective graphs for shear thinning fluids are shown in Figures 4 and 7.

\section{Conclusion}

We have considered equations for steady, nonisothermal thin film flows for lifting and drainage problems in cylindrical coordinates of modified second grade fluid. In both cases, series solutions are obtained. Explicit expressions are given, 


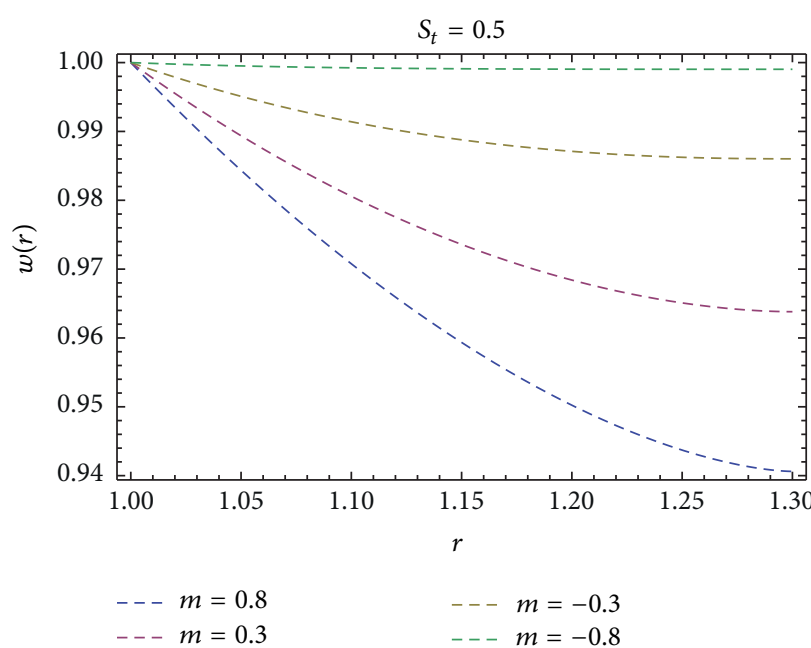

(a)

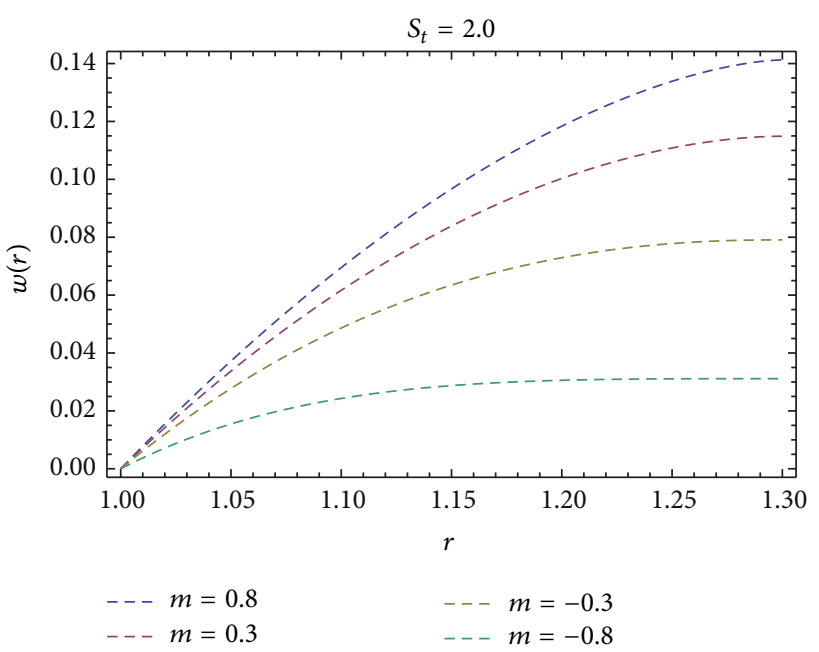

(b)

FIGURE 2: Effect of $m$ on velocity for lifting problem (a) and drainage problem (b).

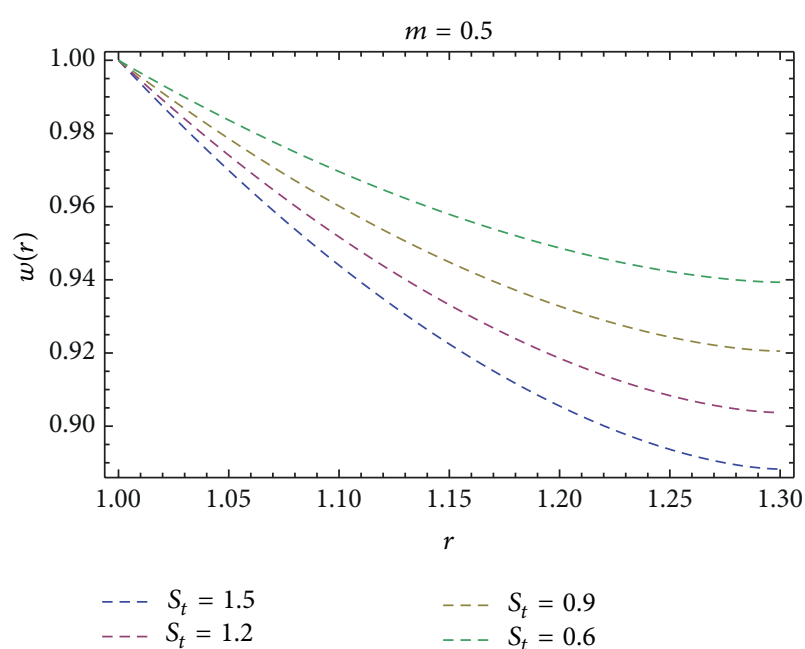

(a)

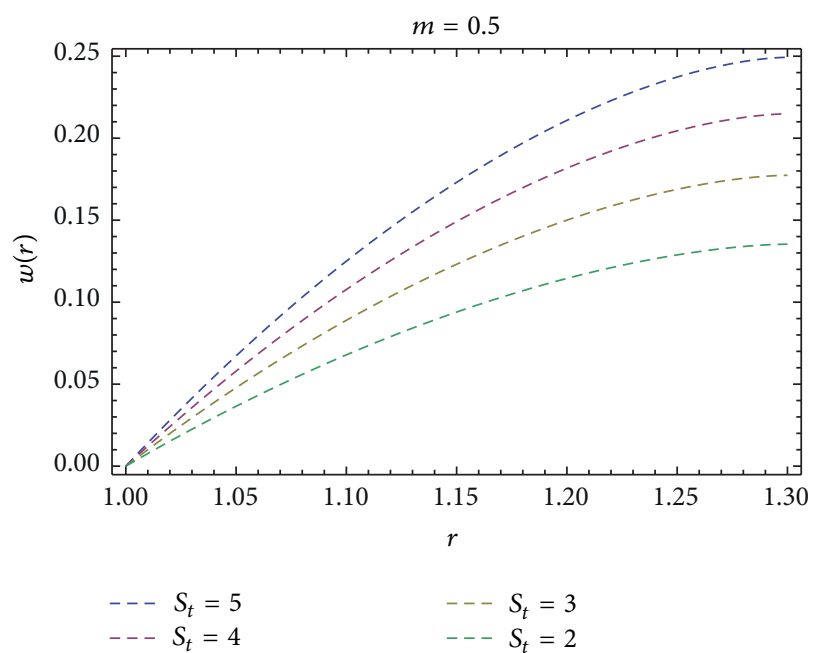

(b)

FIGURE 3: Effect on shear thickening fluid of $S_{t}$ number on velocity for lifting problem (a) and drainage problem (b).

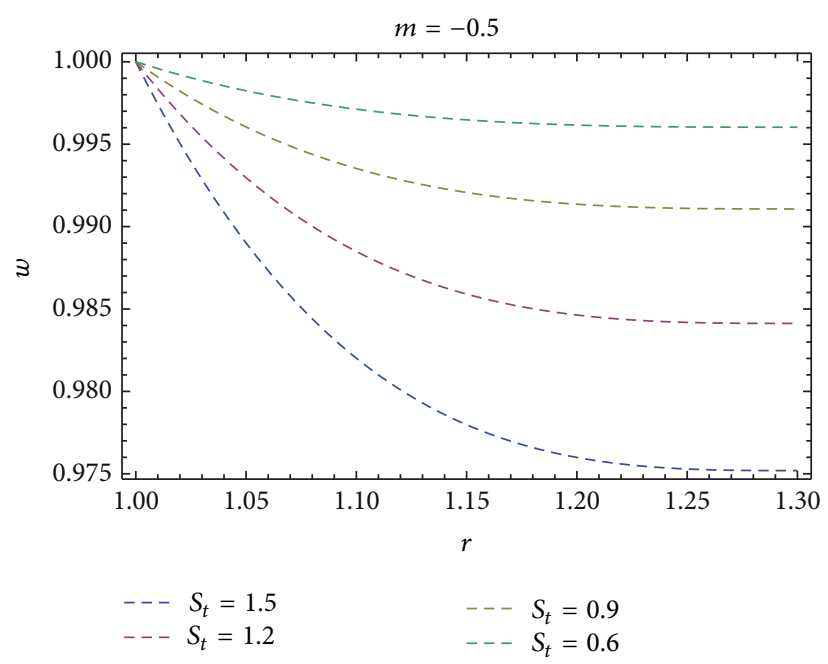

(a)

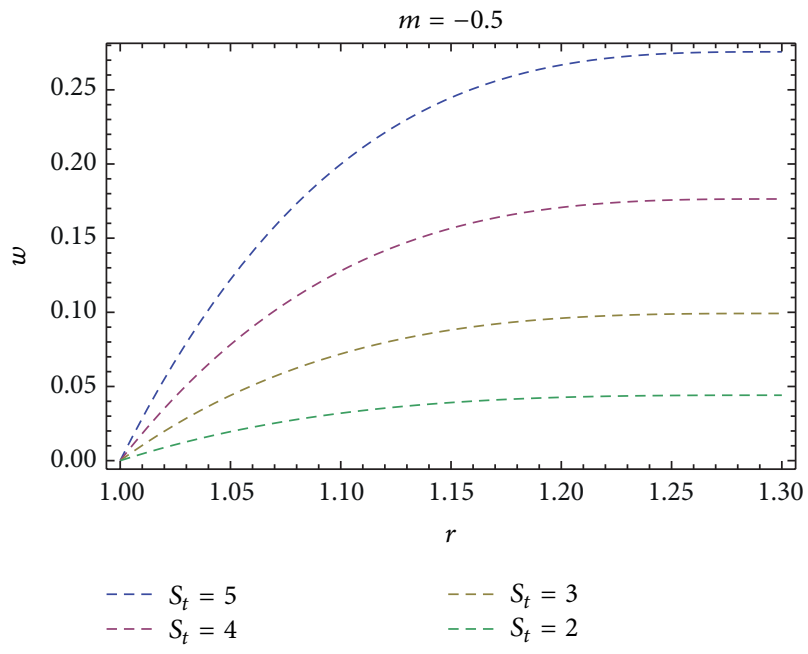

(b)

FIGURE 4: Effect on shear thinning fluid of $S_{t}$ number on velocity for lifting problem (a) and drainage problem (b). 


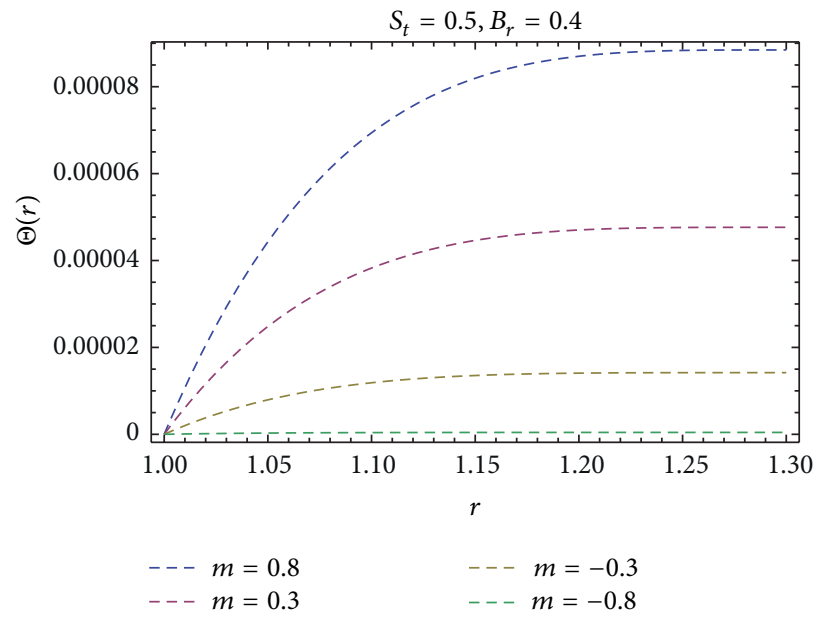

FIGURE 5: Effect of $m$ on temperature for both problems.

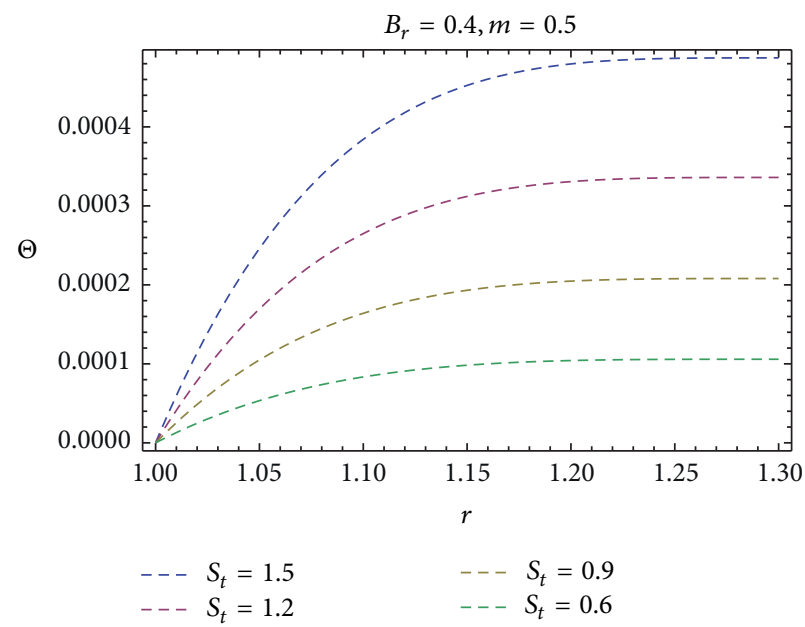

(a)

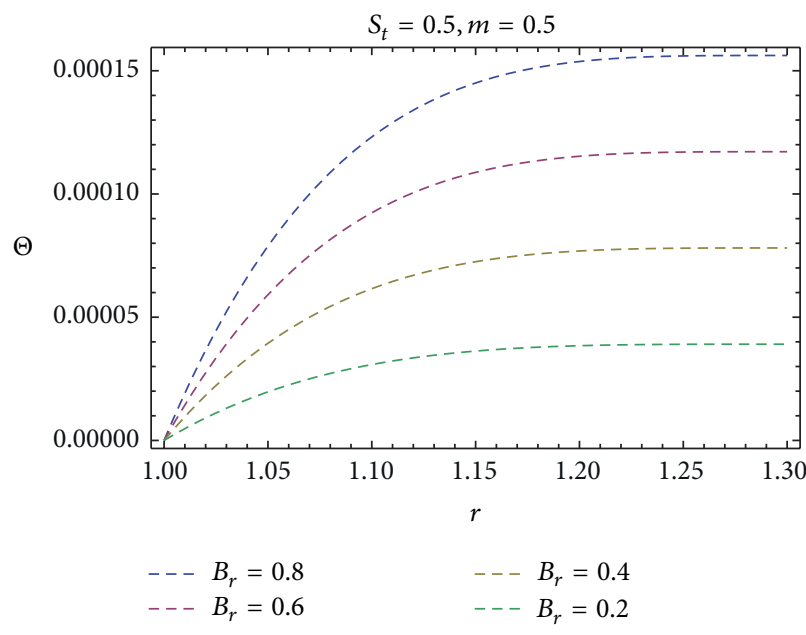

(b)

Figure 6: Effect on shear thickening fluid of $S_{t}$ and $B_{r}$ numbers on temperature for both problems.

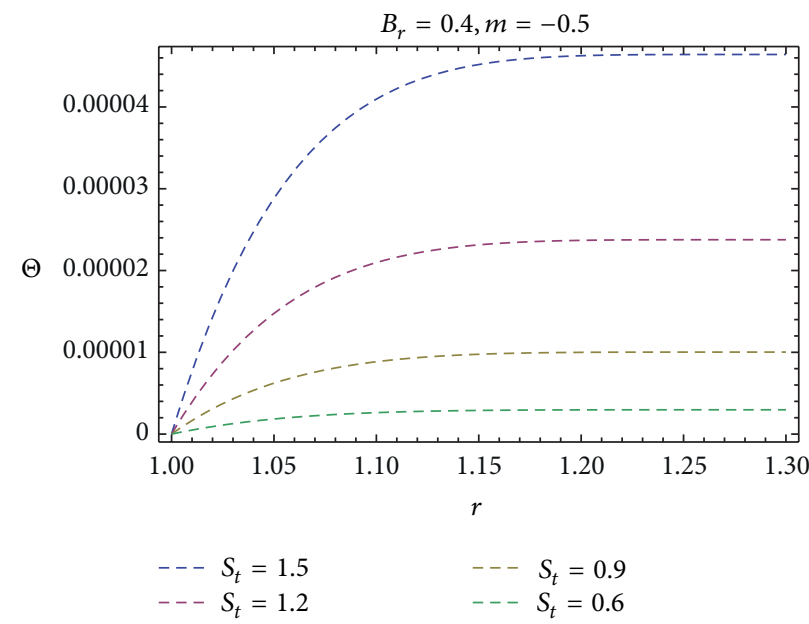

(a)

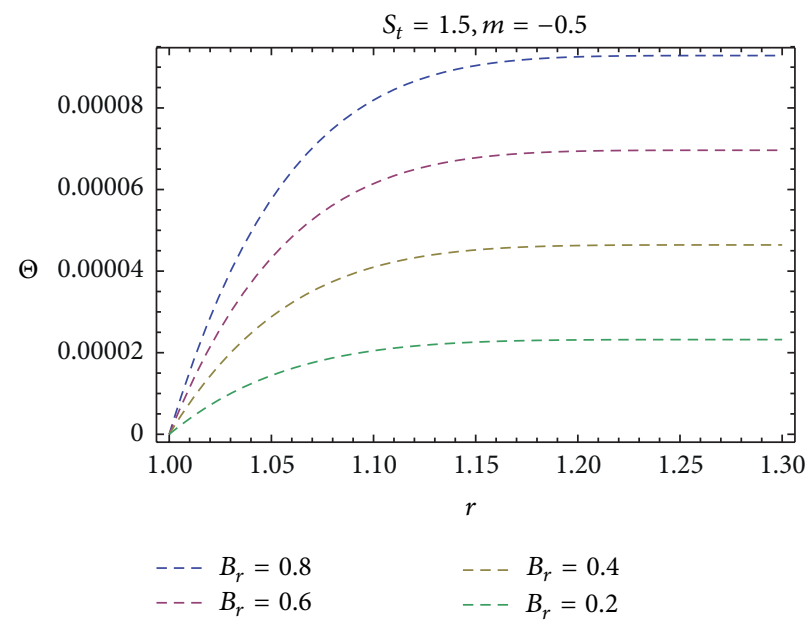

(b)

FIGURE 7: Effect on shear thinning fluid of $S_{t}$ and $B_{r}$ numbers on temperature for both problems. 
in both problems, for the velocity field, temperature distribution, volume flux, average film velocity, and shear stress on cylinder. It is worth mentioning that normal stresses have no contribution for steady modified second grade fluid flow. We do not see any contribution of modified second grade fluid model verses power law model as solutions (18) and (29) for velocity profiles and also (19) and (30) for temperature distributions are the same as those of the power law fluid.

\section{Nomenclature}

$\begin{array}{ll}\text { V: } & \text { Velocity vector } \\ \mathbf{f :} & \text { Body force } \\ p: & \text { Dynamic pressure } \\ t: & \text { Time } \\ \mathbf{L}: & \text { Gradient of velocity } \\ C_{p}: & \text { Specific heat } \\ \mathbf{T}: & \text { Extra stress tensor } \\ m: & \text { Flow behavior index } \\ \mathbf{A}_{1}, \mathbf{A}_{2}: & \text { Rivlin Ericksen tensors } \\ g: & \text { Gravitational acceleration } \\ R: & \text { Radius of cylinder } \\ r, \theta, z: & \text { Coordinate directions } \\ u, v, w: & \text { Velocity components in } r, \theta, z \text { directions } \\ S_{t}: & \text { Stokes number } \\ B_{r}: & \text { Brinkman number } \\ Q: & \text { Volume flux } \\ \bar{V}: & \text { Average velocity } \\ U: & \text { Velocity of fluid at the surface of cylinder } \\ V_{0}: & \text { Velocity of cylinder. }\end{array}$

\section{Greek Letters}

$\begin{array}{ll}\rho: & \text { Density } \\ \Theta: & \text { Temperature } \\ \Theta_{0}: & \text { Temperature at the surface of cylinder } \\ \Theta_{1}: & \text { Reference temperature } \\ \kappa: & \text { Thermal conductivity } \\ \alpha_{1}, \alpha_{2}: & \text { Normal stress coefficients } \\ \mu_{\text {eff }}: & \text { Effective viscosity } \\ \eta: & \text { Flow consistency index } \\ \delta: & \text { Thickness of film. }\end{array}$

\section{Conflict of Interests}

The authors declare that there is no conflict of interests regarding the publication of this paper.

\section{References}

[1] A. M. Siddiqui, R. Mahmood, and Q. K. Ghori, "Some exact solutions for the thin film flow of a PTT fluid," Physics Letters A, vol. 356, no. 4-5, pp. 353-356, 2006.

[2] A. M. Siddiqui, R. Mahmood, and Q. K. Ghori, "Homotopy perturbation method for thin film flow of a fourth grade fluid down a vertical cylinder," Physics Letters A, vol. 352, no. 4-5, pp. 404-410, 2006.

[3] A. M. Siddiqui, M. Ahmed, and Q. K. Ghori, "Thin film flow of non-Newtonian fluids on a moving belt," Chaos, Solitons \& Fractals, vol. 33, no. 3, pp. 1006-1016, 2007.
[4] A. M. Siddiqui, R. Mahmood, and Q. K. Ghori, "Homotopy perturbation method for thin film flow of a third grade fluid down an inclined plane," Chaos, Solitons \& Fractals, vol. 35, no. 1, pp. 140-147, 2008.

[5] S. Nadeem and M. Awais, "Thin film ow of an unsteady shrinking sheet through porous medium with variable viscosity," Physics Letters A, vol. 372, pp. 4965-4972, 2008.

[6] M. Sajid, N. Ali, and T. Hayat, "On exact solutions for thin film flows of a micropolar fluid," Communications in Nonlinear Science and Numerical Simulation, vol. 14, no. 2, pp. 451-461, 2009.

[7] V. Marinca, N. Herisanu, and I. Nemes, "Optimal homotopy asymptotic method with application to thin film flow," Central European Journal of Physics, vol. 6, no. 3, pp. 648-653, 2008.

[8] J. E. Dunn and K. R. Rajagopal, "Fluids of differential type: critical review and thermodynamic analysis," International Journal of Engineering Science, vol. 33, no. 5, pp. 689-729, 1995.

[9] C. Truesdell and W. Noll, "The non-linear field theories of mechanics," in Handbuch der Physik, HI/3, Springer, Berlin, Germany, 1965.

[10] M. Khan, S. Nadeem, T. Hayat, and A. M. Siddiqui, "Unsteady motions of a generalized second grade fluid," Mathematical and Computer Modelling, vol. 41, no. 6-7, pp. 629-637, 2005.

[11] T. Hayat and M. Khan, "Homotopy solutions for a generalized second-grade fluid past a porous plate," Nonlinear Dynamics, vol. 42, no. 4, pp. 395-405, 2005.

[12] M. Khan, Hashim, and C. Feteacu, "On the exact solutions for oscillating ow of an MHD second grade uid through porous media," Special Topics and Reviews in Porous Media, vol. 3, no. 1, pp. 13-22, 2012.

[13] M. Khan, T. Safdar, and M. Azram, "Starting solution for some oscillatory rotating ows of MHD second grade uid through porous space," Journal of Porous Media, vol. 14, no. 8, pp. 723734, 2011

[14] H. I. Andersson and D. Y. Shang, "An extended study of the hydrodynamics of gravity-driven film flow of power-law fluids," Fluid Dynamics Research, vol. 22, pp. 345-357, 1998.

[15] B. K. Rao, "Heat transfer to a falling power-law fluid film," International Journal of Heat and Fluid Flow, vol. 20, pp. 429436, 1999.

[16] D. Y. Shang and H. I. Andersson, "Heat transfer in gravitydriven film flow of power-law fluids," International Journal of Heat and Mass Transfer, vol. 42, pp. 2085-2099, 1999.

[17] N. V. Lavrik, C. A. Tipple, M. J. Sepaniak, and D. Datskos, “Gold nano-structures for transduction of biomolecular interactions into micrometer scale movements," Biomedical Microdevices, vol. 3, no. 1, pp. 35-44, 2001.

[18] M. Massoudi and T. X. Phuoc, "Flow of a generalized second grade non-Newtonian fluid with variable viscosity," Continuum Mechanics and Thermodynamics, vol. 16, no. 6, pp. 529-538, 2004.

[19] C. Wang and I. Pop, "Analysis of the flow of a power-law fluid film on an unsteady stretching surface by means of homotopy analysis method," Journal of Non-Newtonian Fluid Mechanics, vol. 138, pp. 161-172, 2006. 


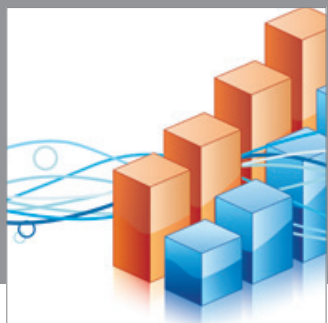

Advances in

Operations Research

mansans

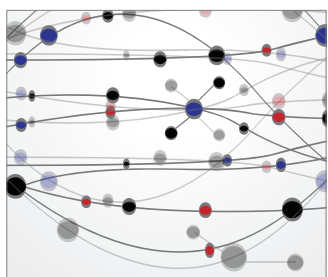

The Scientific World Journal
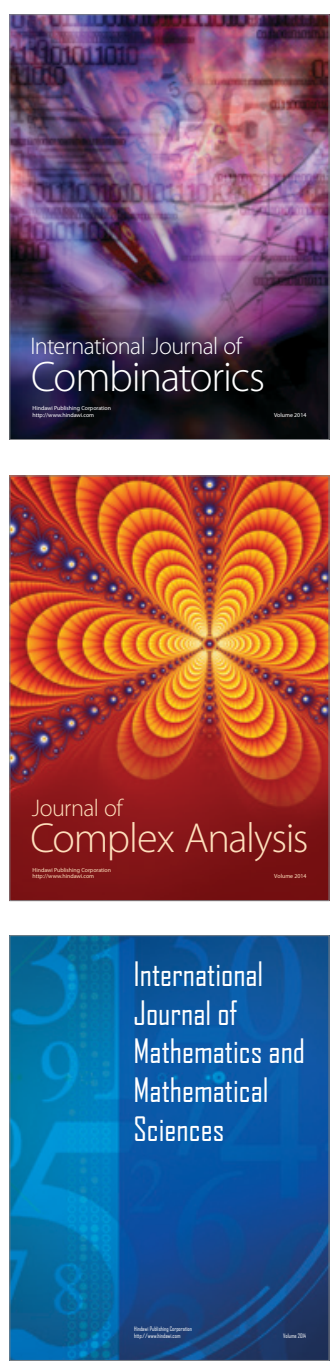
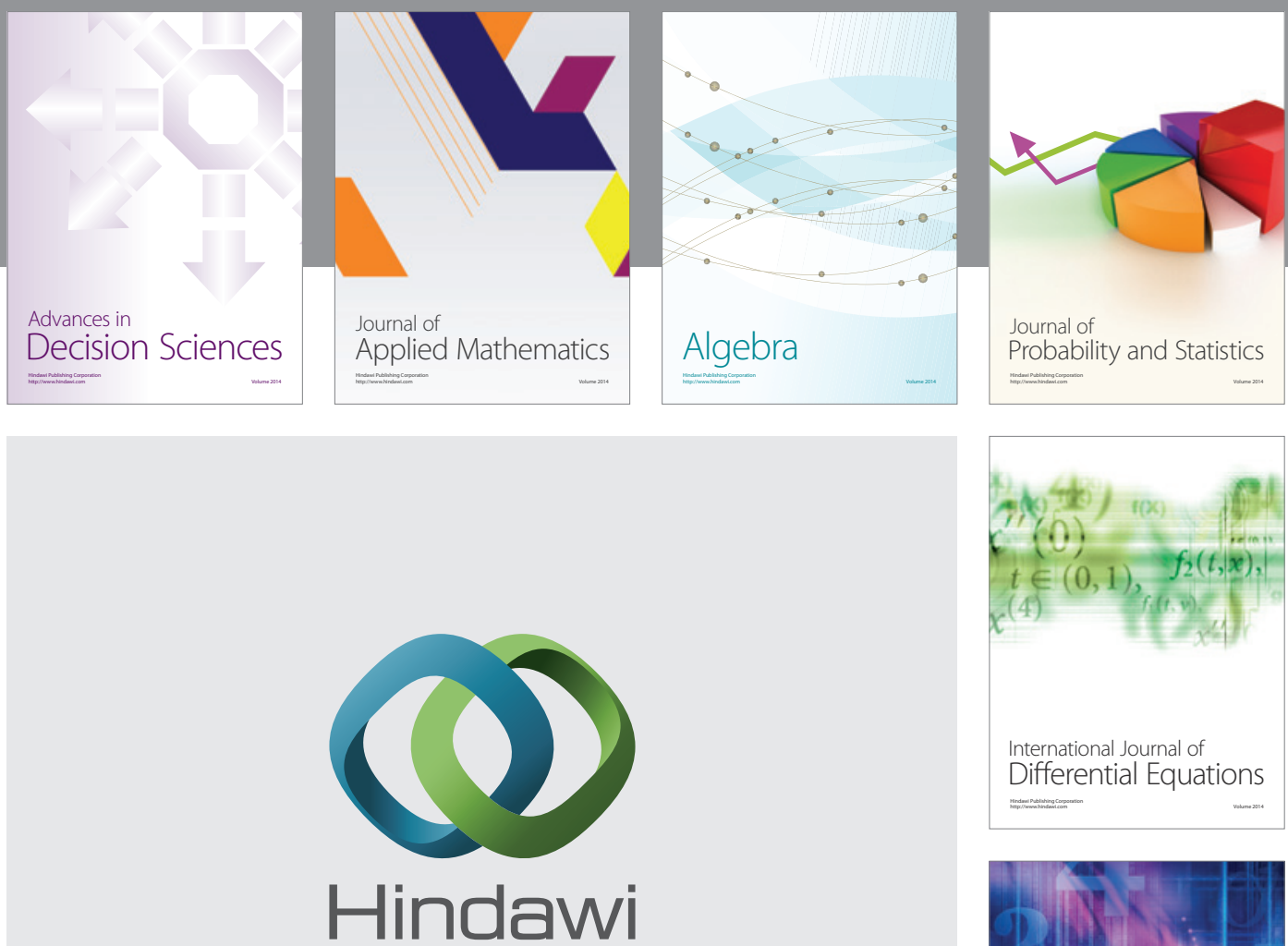

Submit your manuscripts at http://www.hindawi.com
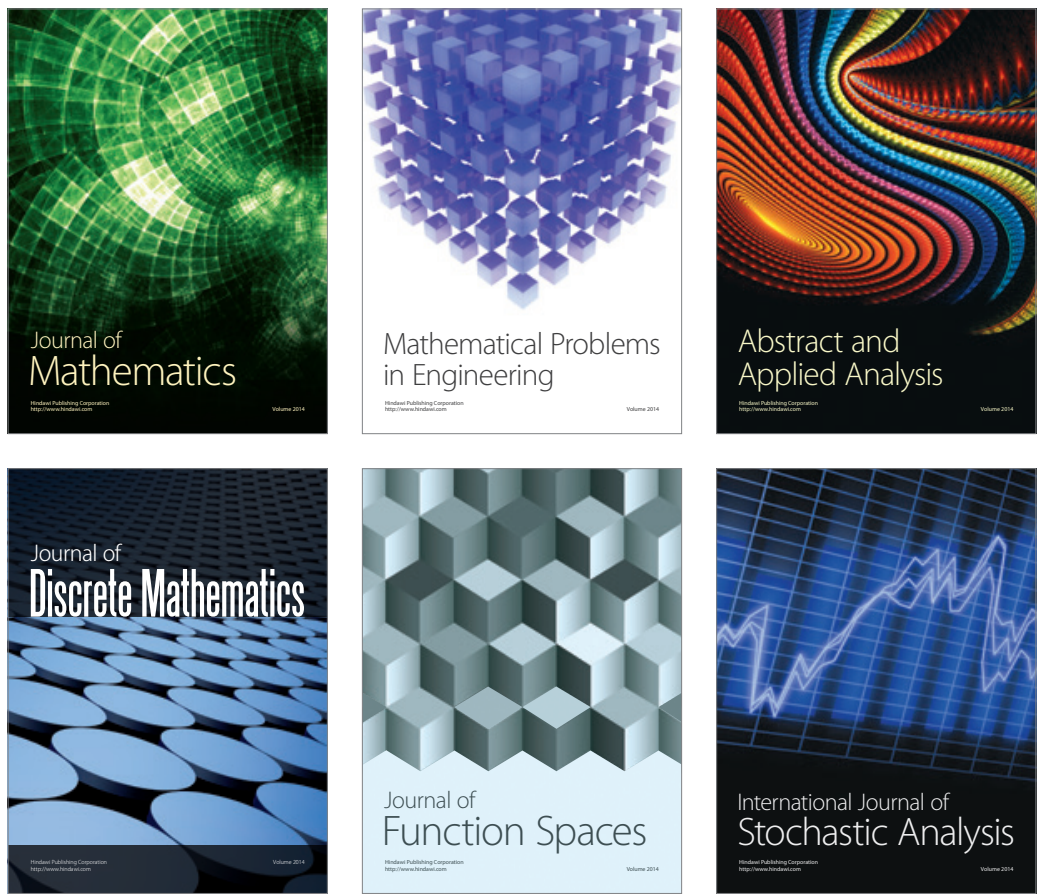

Journal of

Function Spaces

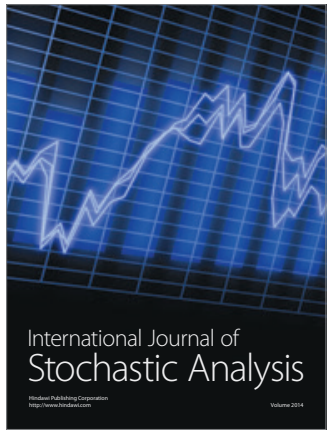

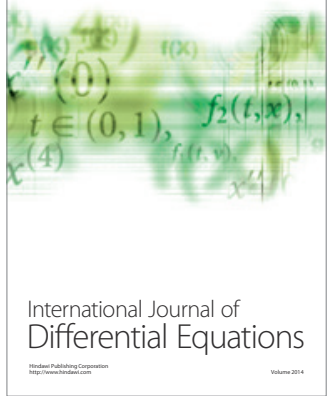
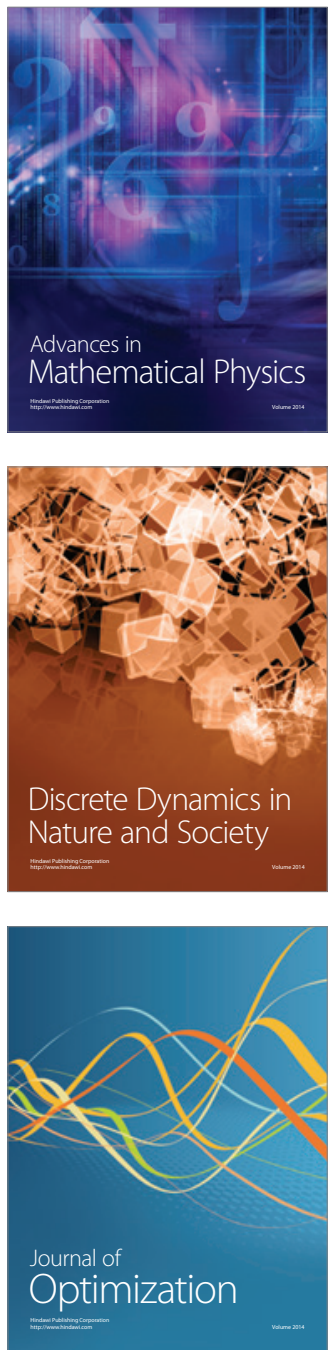